\title{
The "Yin and Yang" of Platelet-rich Plasma in Breast Reconstruction After Mastectomy or Lumpectomy for Breast Cancer
}

\author{
ELEFTHERIOS SPARTALIS ${ }^{1,2}$, DIAMANTIS I. TSILIMIGRAS ${ }^{1}$, PETROS CHARALAMPOUDIS $^{3,4}$, \\ GEORGIA-SOFIA KARACHALIOU ${ }^{1}$, DEMETRIOS MORIS ${ }^{5}$, ANTONIOS ATHANASIOU ${ }^{6}$, \\ MICHAEL SPARTALIS ${ }^{1}$, VASILEIOS BOLKAS ${ }^{1}$, DIMITRIOS DIMITROULIS ${ }^{2}$ and NIKOLAOS NIKITEAS ${ }^{1,2}$ \\ ${ }^{1}$ Laboratory of Experimental Surgery and Surgical Research, University of Athens Medical School, Athens, Greece; \\ ${ }^{2}$ Second Department of Propaedeutic Surgery, Laiko General Hospital, \\ University of Athens Medical School, Athens, Greece; \\ ${ }^{3}$ Breast Unit, Guy's \& St Thomas' NHS Foundation Trust, Great Maze Pond, London, U.K.; \\ ${ }^{4}$ Division of Cancer Studies, King's College London, London, U.K.; \\ ${ }^{5}$ Division of Surgical Oncology, The Ohio State University Wexner Medical Center and \\ James Cancer Hospital and Solove Research Institute, Columbus, OH, U.S.A.; \\ ${ }^{6}$ Department of Surgery, University Hospitals Birmingham NHS Foundation Trust, \\ Queen Elizabeth Hospital, Birmingham, U.K.
}

\begin{abstract}
Surgery remains the mainstay of treatment for breast cancer, including complete or partial mastectomy and lumpectomy. Breast reconstruction has gained popularity mainly due to its tremendous impact on the psychological status of the patients. Autologous fat grafting is a wellestablished method used in cosmetic surgery; however, fat reabsoprtion, fat necrosis, calcifications and oil-cyst formation are some usually encountered complications limiting the efficacy of this approach. Platelet-rich plasma (PRP) has recently been postulated as a promising method for tissue regeneration since it contains high levels of diverse human growth factors. To date, preliminary results from clinical studies regarding the combination of PRP and fat grafting in breast reconstruction have shown ambiguous results, whereas preclinical studies are more favorable. However, concerns have been raised regarding the extent of cellular promotion induced by PRP application and the corresponding potential malignant transformation. The aim of our study was to present, analyze and critically evaluate the role of PRP in
\end{abstract}

Correspondence to: Eleftherios Spartalis, MD, MSc, Ph.D., Vasilissis Sofias 49, Athens 106 76, Greece. Tel: +30 6974714078, Fax: +30 2106416015, e-mail: eleftherios.spartalis@gmail.com

Key Words: Platelet-rich plasma, breast reconstruction, mastectomy, breast cancer, review. breast reconstruction after breast cancer surgery in terms of efficacy and oncological safety highlighting the caution that needs to be taken in order to eliminate any chance of recurrence in patients who have theoretically undergone complete excision of the tumor burden.

Breast cancer represents the most common cancer in the female population with approximately 40,000 breast cancer deaths occurring in the US each year (1). Surgery remains the mainstay of treatment, including complete or partial mastectomy and lumpectomy that can be further accompanied by breast reconstruction $(2,3)$. Traditionally, prosthetic implants or autologous flaps have been utilized either in a one- or two-stage procedure following a diverse period of time after primary intervention $(2,4)$.

Over the years, autologous fat transplantation has been increasingly used for reconstruction after mastectomy or breast conserving surgery (BCS) for breast cancer (5). Autologous fat consists of adipose-derived stem cells (ASCs) that may hold promise as a regenerative medium due to their inherent ability to promote the healing process through in situ differentiation and secretion of paracrine factors $(4,5)$.

In order to further enhance the regenerative potential of autologous fat, a wide variety of biochemical factors have been used targeting the proliferation and the differentiation processes of stem cells. Among them, platelet-rich plasma (PRP) has recently been postulated as a promising method 
for tissue regeneration since it contains high levels of diverse human growth factors (6). Nevertheless, the exact underlying mechanisms of tissue regeneration following PRP fat grafting remain under investigation. In addition, although PRP is thought to enhance the sustainability of the injected fat, a few relative contraindications have been suggested raising concerns regarding its potential oncological effect on the tumor bed after cancer resection (7).

\section{Materials and Methods}

An exhaustive literature search with regards to the PRP and its use in breast reconstruction was performed using PubMed (Medline), Cochrane Library/Cochrane Register of Controlled Trials, EMBASE, AMED (Allied and Complimentary Medicine Database), CINAHL (Cumulative Index to Nursing and Allied Health Literature), PsycINFO, ISI Web of Science (WoS), BIOSIS, LILACS (Latin American and Caribbean Health Sciences Literature), ASSIA (Applied Social Sciences Index and Abstracts), SCEH (NHS Evidence Specialist Collection for Ethnicity and Health) and SCIRUS databases through June 26th, 2017. The authors also looked at just-in-time (JIT) medical feed sources as returned from Terkko (provided by the National Library of Health Sciences - Terkko at the University of Helsinki). The following MESH terms were used in combination with Boolean operators (AND, OR, NOT): "plateletrich plasma", "plasma-rich growth factors", "platelet concentrate", "platelet-rich gel", "breast cancer", "mastectomy" and "lumpectomy". Two independent authors (ES, DM) screened all articles retrieved by the initial search as well as the reference lists of the relevant studies. Available data were only narratively presented along with critical insights and no statistical analysis was attempted.

\section{Post-Mastectomy Breast Reconstruction: The Past}

Since the first radical mastectomy in 1894 by William Halsted (8), surgical techniques have significantly evolved providing the patients with outstanding survival rates. However, besides eliminating the tumor burden, cosmetic results also play a pivotal role on the psychological status of the patients and, therefore, breast reconstruction has been at the forefront of plastic and breast surgeons' clinical practice (9).

Historically, the first autogenous breast reconstruction was attempted in 1895 by Czerny using a fist-sized lipoma from the lumbar region to fill a post-surgical skin defect (8). Later, in 1906, an Italian surgeon named Tanzini first introduced the utility of a musculocutaneous flap in breast reconstruction using a pedicled flap of skin and latissimus dorsi muscle (8). Over the years, several muscles, as well as flaps from different regions were utilized $(8,10,11)$, while the first two-stage reconstruction took place in 1974 using a thoracoepigastric flap and a prosthetic implant $(8,12)$. In 1962, first-generation silicone breast implants were introduced while saline breast implants were created in $1965(13,14)$. Since then, implants have evolved significantly so that today fifth-generation silicone gel implants are broadly on the market as superior to their predecessors in almost every way (13).
The expander-based breast reconstruction appeared in 1976 and has gained popularity as it aids in recreating the lost skin progressively after mastectomy (2, 15). Skin expansion requires regular visits to the surgeon so that the desired outcome is obtained (2). In 1984, Becker et al. introduced a dual-chamber expander that consisted of two parts; a silicone gel lumen and an enveloped inflatable saline lumen that could be modified appropriately so that the desirable breast size was achieved without necessitating further interventions (16). In an effort to restore the breast volume without using implants, Hartrampf et al. first used the cranially pedicled rectus abdominis muscle flap with a horizontally oriented adipocutaneous skin island (TRAM flap) that was directly supplied by the deep superior epigastric artery (17). Furthermore, in 1979, Holmstrom et al. used an abdominoplasty's normal discarded tissue as a free flap and this technique became the standard one for the microvascular autogenous breast reconstruction (18). In case a free TRAM flap was not obtainable, the use of the superior gluteal artery perforator (sGAP) as well as the deep inferior epigastric perforator (DIEP) artery flap had been suggested as an alternative option by Blondeel and Böckx (19) and Allen and Treece (20).

\section{Post-Mastectomy Breast Reconstruction: Fat Grafting}

Nowadays, three types of breast reconstruction are mainly available after breast malignancy resection; i) implant- or expander- based breast reconstruction, ii) breast reconstruction using flaps-vascularized autologous tissue, and iii) fat graftbased breast reconstruction using non-vascularized lipoaspirate fat (2). Over the last 20 years, autologous fat grafting has been one of the most popular options in plastic surgery both in the cosmetic and reconstructive field (21) showing favorable satisfaction rates among patients $(22,23)$. Fat grafting restores the shape and the tissue functionality and is applicable to a wide variety of soft tissue defects mainly of small to medium size avoiding the emerging problems of the other autologousor heterologous- derived biologic materials (5). Additionally, autologous fat grafting provides an aesthetic result closer to that of normal soft tissue (5). However, in cases of mastectomy or wide local excision, implants or flaps may be more appropriate while fat graft may be useful as an adjunct to the aforementioned options, as a side tool for correction of minor defects (5).

A major drawback of autologous fat grafting concerns the maintenance of graft volume, due to postoperative fat reabsorption (24). Currently, long-term data on post fat graft volume maintenance are quite variable, with an observed reabsoprtion and fat necrosis rate ranging between $30 \%$ to $70 \%$ (24, 25); consequently, most patients will have to undergo at least one or two additional sessions of fat graft in 
Table I. Clinical studies reporting on the use of PRP in breast reconstruction.

\begin{tabular}{ll}
\hline Author (year) & Findings \\
\hline Gentile et al. 2013 (26) & $\begin{array}{l}\text { The use of mixed PRP and adipose tissue is a safe method, superior to the fat grafting } \\
\text { alone in terms of restoring and maintaining breast volume }(69 \% \text { s. } 39 \%) .\end{array}$ \\
Salgarello et al. 2011 (28) & $\begin{array}{l}\text { PRP-enriched fat grafting is not superior to the classic Coleman fat grafting alone in } \\
\text { terms of clinical outcomes, rate of satisfaction and incidence of liponecrosis. }\end{array}$ \\
Lersant et al. 2016 (29) & $\begin{array}{l}\text { Lower incidence of hematoma formation in women undergoing breast reduction surgery } \\
\text { with PRP-glue application compared to those without PRP. } \\
\text { Equivalent wound-healing quality. }\end{array}$ \\
\hline
\end{tabular}

order to achieve a satisfactory cosmetic result (25). Apart from that, calcifications and oil-cyst formation are commonly encountered complications following fat grafting (25). It is, therefore, essential to improve fat graft survival and quality so as a desired and durable cosmetic result is achieved.

\section{Post-Mastectomy Breast Reconstruction: Platelet-rich Plasma and Fat Grafting}

Nowadays, efforts have been made aiming to examine the efficiency of fat grafting and PRP combination compared to the fat grafting alone in breast reconstruction (Table I). In that context, Gentile et al. described the use of mixed PRP and adipose tissue as a safe method, superior to the fat grafting alone in terms of restoring and maintaining breast volume (69\% vs. 39\%) (26). This can be, in part, explained by the fact that PRP promotes the proliferation of adiposederived stem cells and dermal fibroblasts (27). On the contrary, Salgarello et al. in a retrospective comparative study reported no superiority of the PRP-enriched fat grafting compared to the classic Coleman fat grafting alone in terms of clinical outcomes, rate of satisfaction and incidence of liponecrosis (28). Recently, however, Hersant et al. revealed a lower incidence of hematoma formation in women undergoing breast reduction surgery with PRP-glue application compared to the control group but equivalent wound-healing quality (29).

While results from clinical studies are rather contradictory, animal studies seem to be more favorable with regard to the use of PRP assisted fat grafting. Injection of PRP plus fat grafting in rabbits showed less inflammatory reaction and fewer oil cysts (30) as well as significantly higher fat survival weight and higher number of viable adipocytes and blood vessels (31) compared to fat grafting alone. The latter was also verified by Nakamura et al. in rats (32). Nevertheless, experiments on nude mice showed ambiguous results; one study revealed the superiority of PRP assisted fat grating in terms of fat graft volume and rate of complications compared to fat graft alone (33), whereas results from another study were comparable between the two groups (34).
There is currently no firm evidence with regard to the ideal PRP concentration needed to combine with fat graft. Recent data showed that microfat mixed with $10 \%$ of PRP presented consistency comparable to stiffer fillers, whereas microfat mixed with 30 or $50 \%$ corresponded to softer fillers (35). This observation allows for choosing the appropriate mixture to meet the needs driven by a specific indication.

\section{Platelet-rich Plasma}

Platelet-rich plasma (PRP) consists of an amount of autologous human platelets in a small volume of plasma (36). The a-granules formation includes seven of the main human growth factors, such as the vascular endothelial growth factor (VEGF), two isomers of the transforming growth factor (TGF- $\beta 1$, TGF- $\beta 2$ ) as well as three isomers of the platelet-derived growth factor (PDGF- $\alpha \alpha$, PDGF- $\alpha \beta$, PDGF- $\beta \beta)(36,37)$.

Following their accumulation, the human growth factors are actively secreted from the a-granules, a process initiated along with the blood clotting cascade. The process begins with ten minutes after clotting, and within an hour, approximately $95 \%$ of the growth factors are released (37). Thus, PRP should be prepared in an anticoagulated state and be applied to the surgical site within ten minutes of clot initiation (38). This is the triggering event that leads to platelet formation; the newly synthesized platelets release additional molecules and proteins to amplify their surveillance for the following five to 10 days to come (38).

\section{Efficacy of PRP}

Due to the inherent properties of human growth factors, PRP is known to promote angiogenesis and differentiation of stem cells, as shown in several experimental protocols to date. Regarding angiogenesis, it has been demonstrated that PRP stimulates the endothelial cells close to the application site, thus favoring proliferation and formation of new capillaries (36). In addition, PRP stimulates the proliferation of undifferentiated stem cells, thus amplifying tissue 
regeneration (39). Consequently, undifferentiated stem cells migrate to the application site, where vascular growth factor is secreted and further proliferation is induced (39).

Furthermore, there have been reports of successful clinical application of PRP in the management of large complex wounds, maxillofacial bone defects, salivary gland tumors and in cosmetic surgery $(40,41)$. However, only a handful of studies have looked at the impact of PRP on the clinical outcomes of its use. Most of these publications pertain to case reports or case series, providing low level of evidence regarding the safety of PRP use. Following that, there have been publications showing that PRP had minimum effect when applied for graft enhancement. This comes from the fact that the PRP production method is not standardized yet and as a result, low quality PRP may be produced by suboptimal devices (37). Data on standardization of the PRP production technique remain scarce (42).

There are no recommendations on how to quanitify the amount of platelets needed above the baseline in PRP. Some investigators suggest that PRP should achieve a three- to eightfold increase in the baseline platelet count (43). Since the normal range of platelets on a healthy individual ranges between 150 and $400 \times 10^{3} / \mathrm{ml}$ (mean value $=275 \times 10^{3} / \mathrm{ml}$ ), an increase to at least a count of $775 \times 10^{3} / \mathrm{ml}$ is required. When it comes to the production process, centrifugation should be performed under sterile conditions, and complete separation between platelets and red blood cells should be aimed for maintaining platelets intact in order to accomplish the secretion of human growth factors along with the platelets isolation procedure.

\section{Safety of PRP - Infection}

Given that PRP derives from autologous tissue, it is considered safe from an infectious potential perspective, as long as the host is free of transmitable diseases such as HIV, hepatitis and others (37). However, the safety of PRP with regards to sterility when used in breast reconstruction remains to be clarified. One could argue that blood agar (into which the produced PRP is contained) is a material prone to bacterial infections. However, this can be ruled out because PRP is no different than a normal blood clot formed in a wound (38).

Moreover, another challenging issue is the sterility maintained during processing of the PRP (36). In contrast to the early years of PRP production, however, various companies have developed clinical autologous platelet concentrate machines that eliminate almost every possibility of occult infection.

\section{The Oncological Safety of PRP}

The principal debate around PRP use in cancer surgery pertains to whether it is oncologically safe to apply PRP to sites where cancer has been earlier developed and excised
(44-51). To date, data on the use of PRP as an adjunct to breast reconstruction after cancer treatment remain limited as opposed to adipose-derived stem cells (ASCs) or autologous fat grafting (38). Because of the ability of activated PRP to promote human ASCs and dermal fibroblast proliferation, primarily through induction of high levels of PDGF-AB and TGF- $\beta 1$ (27), and due to the fact that agranules of platelets include molecules such as PDGF and VEGF known to mediate tumor cells interactions, concerns have been raised regarding the extent of cellular promotion and the corresponding potential malignant transformation.

Several studies on cancer growth, recurrence and postoperative survival rate, focus on the tumor stroma, which represents a crucial parameter in tumor development $(7,52)$. Growth factors and molecules such as PDGF, VEGF, EGFR (HER) and TGF-b mediate the interactions that render tumor cells immortal, including angiogenesis, lymphagiogenesis, constant proliferation, abnormal differentiation and apoptosis avoidance $(51,53)$. In addition, literature suggests that patients with breast tumors positive for PDGF have a significantly lower response rate to chemotherapy and significantly shorter duration of survival while plasma levels of PDGF also correlate with shorter survival (54). Of note, experimental data have shown that breast tumor stroma increases luminal breast cancer cell proliferation and angiogenesis through PDGF signaling pathway (55). Therefore, induction of such growth factors by the PRP application to an area of a previously developed malignancy could trigger a neoplastic proliferation process from the residual cells.

\section{Conclusion}

Although the hypothesis of PRP-related malignant transformation has not been proven, it is of great importance to eliminate any chance of recurrence in patients who have theoretically undergone complete excision of the tumor burden. Therefore, further in vitro experiments and animal studies are encouraged so that the interactions of PRP in areas of cancer excision are thoroughly investigated. Since no established indication of PRP use in breast reconstruction exists, we consider the use of the platelet-rich plasma not yet indicated in patients undergoing resection for cancer.

\section{References}

1 DeSantis CE, Fedewa SA, Goding Sauer A, Kramer JL, Smith RA and Jemal A: Breast cancer statistics, 2015: Convergence of incidence rates between black and white women. CA Cancer J Clin 66: 31-42, 2016.

2 Schmauss D, Machens HG and Harder Y: Breast reconstruction after mastectomy. Front Surg 2: 71, 2015.

3 Tsilimigras DI, Ntanasis-Stathopoulos I, Schizas D, Bakopoulos A, Moris D, Stanc GM, Tentolouris A, Nassar S and Salla C: Combined use of mammography and FNA eliminates pitfalls in the management of metaplastic breast carcinoma. In Vivo 31: 737-740, 2017. 
4 Tsekouras A, Mantas D, Tsilimigras DI, Ntanasis-Stathopoulos I, Kontos M and Zografos GC: Adipose-derived stem cells for breast reconstruction after breast surgery - preliminary results. Case Reports Plast Surg Hand Surg 4: 35-41, 2017.

5 Simonacci F, Bertozzi N, Grieco MP, Grignaffini E and Raposio E: Autologous fat transplantation for breast reconstruction: A literature review. Ann Med Surg (Lond) 12: 94-100, 2016.

6 Spartalis E, Tomos P, Moris D, Athanasiou A, Markakis C, Spartalis MD, Troupis T, Dimitroulis D and Perrea D: Role of platelet-rich plasma in ischemic heart disease: An update on the latest evidence. World J Cardiol 7: 665-670, 2015.

7 Spartalis ED, Tomos P, Konofaos P, Dimitroulis D and Kouraklis $\mathrm{G}$; Breast reconstruction with autologous fat graft; does plateletrich plasma affect patient's survival? Int J Clin Exp Med 7: 329330,2014

8 Uroskie TW and Colen LB: History of breast reconstruction. Semin Plast Surg 18: 65-69, 2004.

9 Kaya B and Serel S: Breast reconstruction. Exp Oncol 35: 280286, 2013

10 Teimourian B and Adham MN: Louis Ombredanne and the origin of muscle flap use for immediate breast mound reconstruction. Plast Reconstr Surg 72: 905-910, 1983

11 Lynch JB, Madden JJ Jr. and Franklin JD: Breast reconstruction following mastectomy for cancer. Ann Surg 187: 490-501, 1978.

12 Hohler H: Carcinoma of the breast. Reconstructive surgery. Langenbecks Arch Chir 345: 78-86, 1977.

13 Baek WY, Lew DH and Lee DW: A retrospective analysis of ruptured breast implants. Arch Plast Surg 41: 734-739, 2014.

14 Maxwell GP and Gabriel A: Possible future development of implants and breast augmentation. Clin Plast Surg 36: 167-172, 2009.

15 Radovan C: Breast reconstruction after mastectomy using the temporary expander. Plast Reconstr Surg 69: 195-208, 1982.

16 Becker $\mathrm{H}$ : Breast reconstruction using an inflatable breast implant with detachable reservoir. Plast Reconstr Surg 73: 678683, 1984.

17 Hartrampf CR, Scheflan M and Black PW: Breast reconstruction with a transverse abdominal island flap. Plast Reconstr Surg 69: 216-225, 1982.

18 Holmstrom H: The free abdominoplasty flap and its use in breast reconstruction. An experimental study and clinical case report. Scand J Plast Reconstr Surg 13: 423-427, 1979.

19 Blondeel PN and Boeckx WD: Refinements in free flap breast reconstruction: the free bilateral deep inferior epigastric perforator flap anastomosed to the internal mammary artery. $\mathrm{Br}$ J Plast Surg 47: 495-501, 1994.

20 Allen RJ and Treece P: Deep inferior epigastric perforator flap for breast reconstruction. Ann Plast Surg 32: 32-38, 1994.

21 Rigotti G, Marchi A, Galie M, Baroni G, Benati D, Krampera M, Pasini A and Sbarbati A: Clinical treatment of radiotherapy tissue damage by lipoaspirate transplant: a healing process mediated by adipose-derived adult stem cells. Plast Reconstr Surg 119: 1409-1422; discussion 1423-1404, 2007.

22 Weichman KE, Broer PN, Tanna N, Wilson SC, Allan A, Levine JP, Ahn C, Choi M, Karp NS and Allen R: The role of autologous fat grafting in secondary microsurgical breast reconstruction. Ann Plast Surg 71: 24-30, 2013.

23 Brown AWW, Kabir M, Sherman KA, Meybodi F, French JR and Elder EB: Patient reported outcomes of autologous fat grafting after breast cancer surgery. Breast 35: 14-20, 2017.
24 Pinski KS and Roenigk HH, Jr: Autologous fat transplantation. Long-term follow-up. J Dermatol Surg Oncol 18: 179-184, 1992.

25 Groen JW, Negenborn VL, Twisk DJ, Rizopoulos D, Ket JC, Smit JM and Mullender MG: Autologous fat grafting in oncoplastic breast reconstruction: A systematic review on oncological and radiological safety, complications, volume retention and patient/surgeon satisfaction. J Plast Reconstr Aesthet Surg 69: 742-764, 2016.

26 Gentile P, Di Pasquali C, Bocchini I, Floris M, Eleonora T, Fiaschetti V, Floris R and Cervelli V: Breast reconstruction with autologous fat graft mixed with platelet-rich plasma. Surg Innov 20: 370-376, 2013.

27 Kakudo N, Minakata T, Mitsui T, Kushida S, Notodihardjo FZ and Kusumoto K: Proliferation-promoting effect of platelet-rich plasma on human adipose-derived stem cells and human dermal fibroblasts. Plast Reconstr Surg 122: 1352-1360, 2008.

28 Salgarello M, Visconti G and Rusciani A: Breast fat grafting with platelet-rich plasma: a comparative clinical study and current state of the art. Plast Reconstr Surg 127: 2176-2185, 2011.

29 Hersant B, SidAhmed-Mezi M, Lapadula S, Niddam J, Bouhassira J and Meningaud JP: Efficacy of autologous plateletrich plasma glue in weight loss sequelae surgery and breast reduction: a prospective study. Plast Reconstr Surg Glob Open 4: e871, 2016.

30 Rodriguez-Flores J, Palomar-Gallego MA, Enguita-Valls AB, Rodriguez-Peralto JL and Torres J: Influence of platelet-rich plasma on the histologic characteristics of the autologous fat graft to the upper lip of rabbits. Aesthetic Plast Surg 35: 480486, 2011.

31 Pires Fraga MF, Nishio RT, Ishikawa RS, Perin LF, Helene A Jr. and Malheiros CA: Increased survival of free fat grafts with platelet-rich plasma in rabbits. J Plast Reconstr Aesthet Surg 63: e818-822, 2010.

32 Nakamura S, Ishihara M, Takikawa M, Murakami K, Kishimoto S, Nakamura S, Yanagibayashi S, Kubo S, Yamamoto N and Kiyosawa T: Platelet-rich plasma (PRP) promotes survival of fat-grafts in rats. Ann Plast Surg 65: 101-106, 2010.

33 Oh DS, Cheon YW, Jeon YR and Lew DH: Activated plateletrich plasma improves fat graft survival in nude mice: a pilot study. Dermatol Surg 37: 619-625, 2011.

34 Por YC, Yeow VK, Louri N, Lim TK, Kee I and Song IC: Platelet-rich plasma has no effect on increasing free fat graft survival in the nude mouse. J Plast Reconstr Aesthet Surg 62: 1030-1034, 2009.

35 Ghazouane R, Bertrand B, Philandrianos C, Veran J, Abellan M, Francois P, Velier M, Orneto C, Piccerelle P and Magalon J: What about the rheological properties of PRP/microfat mixtures in fat grafting procedure? Aesthetic Plast Surg, 2017. doi: 10.1007/s00266-017-0905-0. [Epub ahead of print]

36 Eppley BL, Pietrzak WS and Blanton M: Platelet-rich plasma: a review of biology and applications in plastic surgery. Plast Reconstr Surg 118: 147e-159e, 2006.

37 Marx RE: Platelet-rich plasma: evidence to support its use. J Oral Maxillofac Surg 62: 489-496, 2004.

38 Choi J, Minn KW and Chang H: The efficacy and safety of platelet-rich plasma and adipose-derived stem cells: an update. Arch Plast Surg 39: 585-592, 2012.

39 Hausman GJ and Richardson RL: Adipose tissue angiogenesis. J Anim Sci 82: 925-934, 2004. 
40 Scala M, Mereu P, Spagnolo F, Massa M, Barla A, Mosci S, Forno G, Ingenito A and Strada P: The use of platelet-rich plasma gel in patients with mixed tumour undergoing superficial parotidectomy: a randomized study. In Vivo 28: 121-124, 2014.

41 Loquercio G, G DIC, Fazioli F, Gallo M, A DEC, Iervolino V, Azzaro R, Petruzziello A, Mattiello A and Cacciapuoti C: Autologous platelet gel improves bone reconstruction of large defects in patients with bone giant cell tumors. In Vivo 29: 533$540,2015$.

42 Zimmermann R, Arnold D, Strasser E, Ringwald J, Schlegel A, Wiltfang $J$ and Eckstein R: Sample preparation technique and white cell content influence the detectable levels of growth factors in platelet concentrates. Vox Sang 85: 283-289, 2003.

43 Gonshor A: Technique for producing platelet-rich plasma and platelet concentrate: background and process. Int J Periodontics Restorative Dent 22: 547-557, 2002.

44 Spartalis E, Moris D, Dimitroulis D and Tomos P: Postresectional airway fistula occlusion via stem-cell transplantation: is it oncologically safe? Ann Thorac Surg 100: 2413-2414, 2015.

45 Spartalis E, Tomos P, Konofaos P, Karagkiouzis G, Levidou G, Kavantzas N, Pantopoulou A, Michail O, Perrea D and Kouraklis G: The effect of autologous platelet-rich plasma on bronchial stump tissue granulation after pneumonectomy: experimental study. ISRN Surg 2013: 864350, 2013.

46 Spartalis E, Dimitroulis D, Markakis C and Tomos P: eComment. Experimental controversy regarding the role of adipose-derived stem cells in surgical oncology. Interact Cardiovasc Thorac Surg 19: 367, 2014.

47 Spartalis E, Tomos P, Dimitroulis D, Karagkiouzis G and Kouraklis G: Bronchiolar-pleural fistula repair with plateletleukocyte rich gel. Eur Rev Med Pharmacol Sci 18: 1842, 2014.

48 Spartalis E, Damaskos C, Athanasiou A, Schizas D, Moris D and Dimitroulis D: Applications of Platelet-Rich Plasma in Lymphedema. Lymphat Res Biol 15: 177-178, 2017.
49 Spartalis E, Damaskos C and Athanasiou A: Safety of plateletrich plasma application in abdominal operations. Bratisl Lek Listy 118: 437, 2017.

50 Spartalis E, Athanasiou A, Spartalis M, Moris D, Papalampros $\mathrm{A}$ and Nikiteas N: Platelet-rich plasma and peripheral nerve regeneration: a potential contraindication to its use after tumor excision. Expert Opin Biol Ther 17: 1045-1046, 2017.

51 Spartalis ED, Tomos P, Dimitroulis D and Kouraklis G: Plateletrich plasma in surgical oncology. Surg Innov 21: 441, 2014.

52 Guo X, Wu Y, Hathaway HJ and Hartley RS: Microenvironmental control of the breast cancer cell cycle. Anat Rec (Hoboken) 295: 553-562, 2012.

53 Levva S, Kotoula V, Kostopoulos I, Manousou K, Papadimitriou C, Papadopoulou K, Lakis S, Koukoulias K, Karavasilis V, Pentheroudakis G, Balassi E, Zagouri F, Kaklamanos IG, Pectasides D, Razis E, Aravantinos G, Papakostas P, Bafaloukos D, Rallis G, Gogas H and Fountzilas G: Prognostic evaluation of epidermal growth factor receptor (EGFR) genotype and phenotype parameters in triple-negative breast cancers. Cancer Genomics Proteomics 14: 181-195, 2017.

54 Seymour L, Dajee D and Bezwoda WR: Tissue platelet derivedgrowth factor (PDGF) predicts for shortened survival and treatment failure in advanced breast cancer. Breast Cancer Res Treat 26: 247-252, 1993.

55 Pinto MP, Dye WW, Jacobsen BM and Horwitz KB: Malignant stroma increases luminal breast cancer cell proliferation and angiogenesis through platelet-derived growth factor signaling. BMC Cancer 14: 735, 2014.

Received August 31, 2017

Revised October 3, 2017

Accepted October 11, 2017 